\title{
ConsciênCIA E TEMPORALIDADE EM EdITH STEIN: $E M$ DIÁLOGO COM HEIDEGGER
}

\author{
Etelvina Pires Lopes Nunes ${ }^{1}$
}

\begin{abstract}
Resumo: O tema consciência e temporalidade é comum à filosofia fenomenológica e hermenêutica. Pretende-se, neste artigo, apresentar a teoria de Edith Stein sobre o tempo, com base na sua obra fundamental: Ser finito e ser eterno. Esta se constrói na esteira da fenomenologia de Husserl e como reação a Sein und Zeit, de Heidegger, ademais, apoiando-se na teoria do ato e da potência de Tomás de Aquino. Stein constrói uma teoria do tempo centrada no presente. Aplicando a fenomenologia às "unidades de vivência" e aos conceitos de "ato" e "potência", de origem tomista, cria o conceito de "atualidade", que compreende as três dimensóes temporais. Criticando Heidegger, a autora sublinha que o "ser do ser finito" é "um ser recebido", o qual se constitui na relação de "abertura" ao "ser eterno". Na conclusão, propóe-se a possibilidade do reencontro com o passado (Heidegger) como análise preparatória para a "abertura" ao ser eterno.
\end{abstract}

Palavras-chave: Temporalidade. Finitude. Atualidade. Presente. "Ser recebido".

\section{INTRODUÇÁO}

Ao se ler atentamente a obra Ser finito e Ser eterno (STEIN, 1972), percebe-se, por um lado, que a temporalidade aparece como fundamental na formulação da sua ontologia; por outro, esta tem a sua base na fenomenologia, uma fenomenologia do ser concreto que se vive a si mesmo. É sobre as bases da fenomenologia que Edith Stein vai articular a constituição do ser finito no diálogo com o Infinito. Como já tinha sido explicitado nas obras anteriores da autora, nomeadamente na sua tese de doutoramento sobre $O$ problema da empatia (STEIN, 2012), a consciência experimenta-se como vivência concreta, num ser que é capaz de sentir, de se vivenciar e, por isso mesmo, capaz de vivenciar também a experiência do outro, como outro em mim.

\footnotetext{
${ }^{1}$ Pós-Doutoramento em Filosofia - Universidade Católica Portuguesa - Centro de Estudos Filosóficos e Humanísticos (CEFH), Braga - Portugal. (D) https://orcid.org/0000-0002-7131-1979 E-mail: enunes@braga.ucp.pt
}

https://doi.org/10.1590/0101-3173.2021.v44n1.06.p95

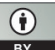

This is an open-access article distributed under the terms of the Creative Commons Attribution License. 
Por isso, um tema importante da obra principal da autora, Ser finito e ser eterno, é o do papel do eu na constituição das vivências e na constituição da consciência. $\mathrm{O}$ eu, não sendo apenas um eu transcendental, como em Husserl, conserva, no entanto, o papel de unificador das vivências; estas, ao fluir, constituem um fluxo cuja unidade é garantida pelo eu, conforme explicita a própria autora:

Podemos tomar o Eu num segundo sentido, enquanto unidade de um fluxo de consciência. Partimos do Eu enquanto sujeito de uma vivência atual. Mas encontramos esta vivência, refletindo sobre ela, não num estado isolado, mas sobre o fundo de um fluxo de tais vivências dadas com uma maior ou menor claridade e distinção. $\mathrm{O}$ Eu desta vivência não esteve sempre nela, mas introduziu-se nela e foi atraído a ela a partir de uma outra, e assim de seguida [...]. É precisamente esta ligação de todas as vivências ao Eu puro que vive no presente, que faz a unidade infrangível deste fluxo. (STEIN, 2012, p. 75).

Como explica Stein, o fluxo das vivências e a qualidade das mesmas, que forma o seu teor, caracterizam a mesmidade e/ou a alteridade do sujeito. $\mathrm{O}$ eu, enquanto unificador das vivências, garante de alguma maneira que estas me pertencem a mim enquanto "eu mesmo". Na passagem acima citada, encontra-se já, precisamente, uma referência ao tempo e ao papel do eu; enquanto as vivências estão em devir e passam, o eu permanece sempre no presente, não passa, como teremos a oportunidade de averiguar, mais adiante.

Qual é então a importância do tempo, na sua relação com a consciência e com a constituição ontológica do homem ou do ser finito, como lhe chama Edith Stein? O tema do tempo aparece inscrito na consciência e no fluxo das vivências. $\mathrm{O}$ eu é, nesse contexto, o que, sem se identificar com as vivências, as une umas às outras, emprestando-lhes a sua vida própria, mas emergindo de cada uma delas. Sobre essa base fenomenológica, Stein elabora a sua ontologia, a qual, por sua ve,z está também inserida numa filosofia da pessoa já formulada nas obras anteriores (STEIN, 1998).

Por isso, Ser finito e ser eterno não é apenas uma obra em diálogo com a fenomenologia e sua relação com o tomismo, mas é uma tentativa de diálogo com a filosofia do seu tempo, quando o problema do ser se cruza com o tema do ser humano enquanto pessoa concreta. Exemplo desse diálogo é o neotomismo, sobretudo de J. Maritain. Porém, como sublinha H.-B. GerlFalkovitz, esse problema estava presente também no âmbito mais próximo da 
fenomenologia, dizia respeito a nomes de primeira ordem, como Heidegger, Conrad-Martius e Przywara (GERL-FALKOVITZ, 1998b). Aliás, o título e o subtítulo da obra de Stein - Ser finito e ser eterno: tentativa de ascensáo ao sentido do ser - mostrariam também esse esforço da parte de Stein, de diálogo com a filosofia do seu tempo, e uma referência, ainda que implícita, de resposta a Heidegger.

Como faz notar H.-B. Gerl-Falkovitz, Edith Stein teria modificado o título da obra, colocando o seu ensaio sobre Heidegger, numa primeira versão, como apêndice a Ser finito e ser eterno (GERL-FALKOVITZ, 1998a; SECRETAN, 1987). ${ }^{2}$ De facto, a leitura de Ser e Tempo teria provocado nela uma forte impressão, e isso a levou, não só a modificar o título da obra, mas já antes, a reformular a obra inicial. Como se sabe, antes de entrar no Carmelo, Edith Stein tinha trabalhado os conceitos de ato e potência de Tomás de Aquino, como preparação do concurso para a habilitação para a docência (SEPP, 2003, p.14-15). É esse manuscrito que lhe será pedido para publicar. Depois de ter feito o noviciado, ao reescrever, saiu algo de completamente novo. Stein retém da obra anterior, no entanto, os conceitos de ato e potência, como ela própria explica:

Durante o ano de 1931 veio à luz um ensaio importante. Este ensaio centrou-se na explicação dos conceitos de ato e potência; esses conceitos também deviam determinar o título do conjunto do ensaio. Quando o autor foi admitido na Ordem das Carmelitas Descalças e completou o ano do noviciado, recebeu o ano seguinte de seus superiores, a ordem de finalizar seu antigo ensaio para que fosse impresso. Foi assim que o autor escreveu uma versão totalmente nova: apenas algumas das páginas (o começo da primeira parte) dos esboços anteriores foram retomadas. Somente o ponto de partida, a saber, a doutrina tomista do ato e da potência, foi conservada. A obra é centrada sobre o problema do ser. (STEIN, 1972, p. 2).

O tempo aparece assim a Edith Stein essencial, não apenas para fundamentar a sua ontologia, mas também para a constituir sobre um tema

\footnotetext{
${ }^{2}$ H.-B. Gerl-Falkovitz escreve: "Allorchè Edith Stein nel 1936 rielaborerà nel Carmelo il suo abozzo incompiuto nella grande opera Endliches und ewiges Sein [...], le diede un sottotitolo quase provocatorio: Saggio (tentativo) di una ascesa al senso dell'essere. In questo modo vienne ripresa la questione fondamentale di Sein und Zeit [...] del 1927 da lei letto 'subito dopo la publicazione e da cui ricevette una forte impressione, senza pero giungere ad afrontare in modo oggetivo il dibatito sull'argomento'.". (GERL-FALKOVITZ, 1998a, p. 143 ; Philibert Secrétan salienta, em nota: "Primitivement publiées en annexe à Endliches und ewiges Sein, les études sur la Philosophie de l'existence de Heidegger ont, par suite, été intégrées au volume VI des Werke. Ces études constituent le chapitre VI du présent ouvrage." (STEIN, 1987, p. 62.)
} 
que era já caro ao seu mestre Husserl. Esse tema tinha sido reformulado numa perspetiva completamente diferente e, se quisermos, nova, por Martin Heidegger. Este não apenas o reelabora numa perspetiva hermenêutica, mas, diferentemente de Agostinho ou de Tomás de Aquino, inscreve a temporalidade como constitutiva do Dasein, dentro de uma óptica da temporalidade intramundana, pois procura compreender o "tempo a partir do tempo", sem o colocar em relação com a eternidade (DASTUR, 2011, p. 566). ${ }^{3} \mathrm{O}$ desafio que se apresenta a Stein, por conseguinte, é o de constituir uma ontologia centrada na pessoa humana concreta, tendo em conta a sua dimensão da finitude. Tal como ilustrou Heidegger, esta faz farte do ser humano, contudo, a autora mostra que essa dimensão requer a "abertura" a um ser que não esteja sujeito ao tempo (STEIN, 1972, p. 59).

Tendo como base a fenomenologia, a sua ontologia inclui o ser temporal como ser finito, mas recorrendo às noçôes de "ato" e "potência" de S. Tomas, elaborará uma teoria do tempo que tem a sua centralidade no presente.

\section{A TEMPORALIDADE DA CONSCIÊNCIA}

Tendo em conta o acima referido, tentemos perceber a dimensão da consciência no seu constituir-se nas vivências, para entendermos como se manifesta a dimensão do tempo e o que ela revela.

\subsection{O EU COMO UNIFICADOR DAS VIVÊNCIAS}

Encontramos na consciência a dimensão da temporalidade, do tempo vivido, como sequência de vivências nas quais o eu vive. $\mathrm{O}$ eu participa de diferentes maneiras da unidade da experiência, vive na experiência e participa dela, mas não faz parte do seu conteúdo, encontra-se para além da experiência (STEIN, 1972, p. 52-53). Enquanto sujeito do vivenciar, a sua vida é sempre atual, sempre presente. Mas tudo o que já foi e tudo o que será depois de tudo isso é a sua vida. "Todos os conteúdos de experiência pertencem ao eu. Ele vive e a vida constitui o seu ser." (STEIN, 1972, p. 54). "O Eu é, portanto sempre atual, está sempre vivo, presente e real. Por outro lado, toda a corrente

3 “[...] penser l'éternité et la mort, c'est précisément ce que conteste radicalement d'entrée de jeu Heidegger dans la conférence intitulée 'Le concept de temps', qu'il prononce en juillet 1924 devant la société de théologie protestante de Marburg. "Il ne s'agit plus, explique-t-il, de considérer que 'le temps trouve sons sens dans l'éternité', mais au contraire de comprendre le temps à partir du temps.'” (DASTUR, 2011, p. 566). 
de experiência lhe pertence: tudo o que se encontra atrás dele e diante dele, o que ele foi ou o que será. Duma maneira geral chamamos tudo isso a sua vida." (STEIN, 1972, p. 57).

Podemos assim averiguar que o eu, para Stein, é um "eu vivo", que vive nas vivências e, enquanto passa de uma vivência para a outra, garante também a unidade do fluxo. O eu mergulha nelas e passa de uma para a outra, e a vida flui (STEIN, 1972, p. 55). É nesse fluir das vivências que se inscreve a dimensáo temporal, pois a concepçáo do tempo, para Stein, pressupóe "um vivido como fluxo", isto é, um durar, que não é um fluir condensado totalmente contínuo como a duré bergsoniana, onde as vivências se fundem e se interpenetram umas nas outras (BERGSON, 1921).

Segundo Stein, existem, porém, "[...] modos originários de dar-se da temporalidade como um todo duradouro, e náo como mera dilataçáo da consciência, a qual nunca poderia ser objetivada enquanto unidade." (FERRER, 1998, p. 843). A vivência presente é atual, contudo, no decurso do fluxo, o que era presente se torna passado e deixa de estar vivo. A vivência passada náo mergulha simplesmente no nada, mas continua de uma outra maneira (STEIN, 1972, p. 55). Ao fluir, a vivência vai perdendo vitalidade e recai no passado, todavia, o eu năo deixa logo a "vitalidade da vivência," mantém-na ainda por um pouco e logo se agarra àquela outra vivência que está emergindo. No fluir da consciência, a vivência que mergulha no passado e perde vida não cai num passado obscuro, mas em um fundo vivencial que também constitui a consciência; embora náo esteja vivo como presente, esse passado tem a possibilidade de atuar e de se tornar vivo. Do mesmo modo, o que não está ainda vivo - o futuro - existe já de uma outra maneira, antes de se tornar vivo (STEIN, 1972, p. 55).

Não sendo propriamente um durar, podemos identificar na consciência uma linha temporal constituída por pontos (punctiforme), alinhada pelo fluxo das vivências. De facto, a linha temporal não pode ser dada vivencialmente, nem nos distintos "agora" que a integram, por serem impedidos pela fugacidade essencial dos seus momentos. Notamos a experiência do durar como um dirigir-se àquele decurso e identificamo-lo como duradouro. As vivências constituem, cada uma em si mesma, uma unidade; têm uma certa duração própria e uma certa intensidade, a qual, ao esvair-se, recai num fundo da consciência e logo é sucedida por uma outra. A coordenação, entre uma unidade de vivência e outra, é feita pelo eu que liga umas vivências às outras, concebidas como "unidades de experiência". "O eu não devém e não passa 
como as unidades de experiência." (STEIN, 1972, p. 54); estas são temporais, o eu vive nelas e passa de uma para a outra e, enquanto tal, é sempre atual.

A unidade do fluxo da consciência pode ser entendida como uma sequência irredutível a outras consciências, que, porém, só pode ser destacada fixando-lhe alguns limites temporais: "[...] desde o seu despertar até agora, e quando se trata de um lapso de consciência determinado, a sua unidade acusa-se entre um e outro ponto de duração, sem por isso sairmos da própria corrente temporal." (FERRER, 1998, p. 844). Encontram-se assim, nessa experiência do durar, algumas modalidades que podem denominar-se modalidades da consciência atual do tempo em contraposição com a consciência inatual (FERRER, 1998, p. 844).

Não é possível conceber a extensão da existência só a partir de uma atualidade puntiforme (STEIN, 1972, p.45). A temporalidade atual é fenomenologicamente extensa, não há intervalos entre uns pontos e os outros, até integrar o continuum. Este constitui uma totalidade contínua dada por um ato descontínuo numa corrente viva. O meu pensamento, as minhas reflexóes, estáo em mim atualmente presentes e reais. No entanto, não comecei a pensar neste momento, o facto de pensar "dura” já desde algum tempo e continuará a durar até que não seja interrompido por uma outra atividade intelectual ou por uma impressão exterior brusca. Durante todo o tempo da sua duração, esse pensamento forma um todo que se constrói no tempo (STEIN, 1972, p. 49).

Encontramos, dessa maneira, duas condiçôes correlativas de toda unidade de experiência temporal: o objeto dado intencionalmente que a especifica, e o eu que com o seu "ato intencional" a unifica (STEIN, 1972; FERRER, 1998, p. 846). Como refere Stein a propósito da experiência do estar alegre, "a vivência do conteúdo da alegria está, portanto, condicionada por dois fatores: o objeto e o eu." (STEIN, 1972, p. 52). O objeto experienciado deixa de estar encadeado no fluir temporal, pois se vive como tal sensação, tal notícia, tal surpresa ou tal alegria. $\mathrm{O}$ passar não deixa marcas em tais conteúdos, mas somente no seu fazer-se consciente para um sujeito, através da sua modificação afetiva corpórea. $\mathrm{O}$ eu, por sua vez, vazio de determinaçóes e que está presente em todas as suas vivências temporais, emerge continuamente com elas, sem desaparecer nelas, permanece o mesmo ao longo de todo o percurso. No entanto, é o eu que atualiza as vivências temporais e empresta-lhe a vida própria (FERRER, 1998, p. 847). A noção da "temporalidade atual", porém, náo pode ser compreendida sem o conceito de potencialidade, o qual é índice da temporalidade ontológica. 


\subsection{A TEMPORALIDADE ATUAL}

$\mathrm{Na}$ temporalidade atual, dirigimo-nos ao que está em curso e identificamo-lo como duradouro, não como duração vivida, mas como o que "duradouramente nos ocupa". É a temporalidade constituída pelos atos conscientes. Num primeiro momento, poderíamos ser tentados a afirmar que a atualidade é o presente; no entanto, o conceito de atualidade é mais vasto, porque, sem o passado que acaba de acontecer e sem o futuro que já começa a emergir, o momento presente não existiria. $\mathrm{O}$ momento presente é, em si mesmo, uma passagem, mas não passagem do não-ser ao ser, nem do ser ao não ser. É passagem de algo intermédio, de algo que já existiu antes, como plenamente vivo; nesse momento, enquanto vivência já passada não o está, mas pode ainda passar de novo ao modo de ser presente e pode ser plenamente viva no futuro; possui, na duração temporal atual, o modo de ser preparatório ao desenvolvimento futuro (STEIN, 1972, p. 45).

Entretanto, o ser da consciência encontra-se no presente, mas de que modo? O presente inclui a potencialidade, isto é: a possibilidade do futuro. Segundo as palavras de Stein:

Conservando na minha memória o meu ser passado e imaginando no meu espírito o meu ser futuro, sem lhe dar estritos limites, obtenho a imagem de um passado e de um futuro, de um ser permanente, quer dizer: de uma extensão da existência [...] mas na realidade o meu ser encontra-se como sobre o gume de uma faca (STEIN, 1972, p. 45).

Nesse "gume de faca" que é o presente, encontra-se, segundo a autora, todo o mistério do tempo, pois o passado e o futuro não são fixos e não contêm nenhum ser permanente; o ser permanente não pode ser explicado através da atualidade punctiforme, por isso, o nascimento ôntico do tempo encontra-se no presente plenamente atual.

O que nos aparece como um ser permanente é uma passagem contínua [...]. A existência atual é um simples ponto de contacto com o ser...num só ponto, "algo de dado", e ao mesmo tempo "enquanto dado" algo de "tirado", um ser suspenso entre o não ser e o ser. (STEIN, 1972, p. 46).

O presente é, por conseguinte, uma passagem, e, nessa passagem, definese o tempo. No sentido estrito, o passado e o futuro náo são pressupostos pelo presente, mas existem com o presente e em relaçáo a ele. Assim, o tempo tem o seu ponto cardeal fixo no presente que passa; podem notar-se aqui algumas 
semelhanças com a noção de tempo em S. Agostinho e também algumas diferenças. ${ }^{4}$ Como pode o tempo que passa não ser apenas o fluir temporal de momento a momento? O conceito de atualidade permite perceber uma certa duração que compreende já, em certa medida, os três tempos, passado presente e futuro. Neste ponto, torna-se mais evidente a aplicação dos conceitos de ato e de potência da filosofia tomista.

\section{Atualidade e Potencialidade}

A atualidade da consciência não pode ser explicada sem se recorrer à noção aristotélico-tomista de ato e potência. Esse tema é retomado por Stein da filosofia neoescolástica, interessada na relação entre fenomenologia e tomismo, mais precisamente do diálogo estabelecido entre a autora e o P. Jesuíta Erich Przywara, entre os anos 1925-1931, o qual viria a escrever uma obra sobre a Analogia entis, fecundada no diálogo entre o tomismo e a fenomenologia (PRZYWARA, 1962). ${ }^{5}$

O outro elemento fundamental desse diálogo foi o trabalho efetuado por Stein sobre o De potentia de S. Tomás (AQUINO, 1991), como preparação para o concurso de habilitação à docência; esse trabalho viria a ser publicado mais tarde com o título Potência e ato. ${ }^{6}$ Todavia, a matriz fenomenológica da

\footnotetext{
${ }^{4}$ Existem semelhanças com a noção de tempo de S. Agostinho. No entanto, para Stein, o presente não pode ser concebido apenas como a distentio animi. Na introdução às Liçóes para uma fenomenologia interna do tempo (HUSSERL, 1994, p. 37), Husserl faz um elogio à conceçáo agostiniana do tempo. Stein conhece essa obra, que foi por ela policopiada e ordenada, antes de ser confiada a Heidegger para a edição, quando a autora renunciou ao cargo de assistente de Husserl. No entanto, a noção do presente de S. Agostinho apresenta semelhanças mas também diferenças com Edith Stein. Em S. Agostinho, é pela memória que se alcança o passado e que se mede o tempo. O tempo que passa é, por um lado, uma sucessão de simultaneidades, mas esse tempo contrasta com a eternidade, quando o tempo é medido na interioridade. Ricoeur, comentando o Livro XI das Confissöes, salienta: "O espírito espera e recorda-se, e contudo, a espera e a memória estáo na alma [...] o contraste concentra-se no presente." (RICOEUR, 1994, p. 38-39). E ainda: "A anterioridade da eternidade com relaçáo ao tempo [...] é dada no contraste entre 'o ser que não foi feito e que, contudo, é' e o ser que tem um antes e um depois, que 'muda' e que 'varia'." (RICOEUR, 1994, p. 43-44).

5 Como refere Stein: "Cet échange d'idées eut une influence déterminante sur la manière de poser le problème pour les deux auteurs. [...] Si l'on compare la voie suivi effectivement dans ce livre à celle jugé nécessaire dans Analogia entis, la pensée historique interne marque ici un recul en face des efforts déployés en vue de la vérité supra-historique." (STEIN, 1972, p. 3-4).

${ }^{6}$ Esse ensaio estaria na base da obra posterior, Ser finito e ser eterno; ao ser reformulada em vista da sua publicação, um ano depois que Edith Stein acabou o noviciado em 1935/1936, tornou-se algo completamente novo. Seria publicado em 1959, em Werke. Para as nossas referências: Potenz und Akt. Studien zu einer Philosophie des Seins. In: Edith Steins Werke, Band XVIII, Herder, Freiburg-Basel-Wien 1998; tr. it., Potenza e atto: studi per una filosofia dell'essere. A cura di A. Ales Bello, Roma: Città Nuova, 2003.
} 
autora e a sua experiência pessoal deram um contorno especial ao tratamento do tema, o qual conjuga sabiamente o método fenomenológico e a tradição metafísica, com os seus interesses antropológicos. A noção de "potencialidade" enseja unir as três séries temporais, como veremos.

Stein (2003, p. 60) chama "[...] ato aquilo em que me encontro como ente: a minha vida atual"; por outro lado, deve-se conceber o ato como ser no durar de uma certa fase, algo que se torna momentaneamente atual e, ao escoar para o passado, torna-se inatualidade. Para Stein, a atualidade implica uma certa duração, é uma atualidade que não é pura, porque contém ser e não ser. Só Deus é actus purus, ilimitado, e, por isso, puramente atual (STEIN , 1972, p. 49). A autora explica, na obra Ato e Potência, que, no que concerne à temporalidade, esses conceitos são considerados apenas na esfera imanente à consciência, ao ser finito e náo têm referência, como para S. Tomás, ao ato puro, ao infinito. Essa atualidade não é pura, entretanto, quanto mais uma criatura participa no ser, tanto maior é a sua atualidade (STEIN, 1972, p. 48).

O termo "potência", por sua vez, é utilizado para o que "ainda não é" e para o que "já não é”, no sentido semelhante ao que Husserl chama de “protensão" e "retensão" (STEIN , 2003, p. 62). Indo para além de S. Tomás, Edith Stein chama ao presente, "atual", enquanto a "potência" pertence ao passado e ao futuro.

O meu ser presente é atual e potencial ao mesmo tempo, real e possível; e na medida em que é real, é a realização duma possibilidade que existia antes. A atualidade e a potencialidade existem como modos de ser no simples fato de ser e podem ser deduzidas dele. (STEIN, 1972, p. 44).

Dessa passagem pode-se depreender que o que é atual é o que é real, é aquilo que no sentido estrito é, porém, como a autora explicita, está em devir, contém a potencialidade do futuro. Em que sentido se pode considerar o ser presente como atual e potencial? Na medida em que o presente só pode ser pensado como "duraçáo temporal”, e enquanto tal, a atualidade contém em si uma potencialidade de algo que já passou, mas que é suscetível de se tornar futuro. 


\subsection{A Centralidade do PRESENTE}

A vida do eu é temporal é vivida no presente e a partir do presente; se, por um lado, se manifesta numa corrente puntiforme, formada por fragmentos intermitentes, por outro, forma um continuum garantido pela "potência"; de facto, no meu eu encontra-se, ao mesmo tempo, o ser atual e potencial (STEIN, 1972, p. 47). Como refere Stein:

O passado em mim é potencial no sentido próprio e verdadeiro, pelo fato que a representação do que se passou implica a possibilidade de passar ao estado que eu vivo presentemente; o ser do passado é o degrau preliminar do ser vivo atualmente e pode progressivamente tornar-se vivo na hora presente. (STEIN, 1972, p. 57).

Conforme se lê já na sua tese de doutoramento, O problema da empatia, $\mathrm{o}$ ato de vontade que não foi cumprido não está morto, mas continua a viver num pano de fundo da consciência, até que chegue a hora quando se possa realizar, quer dizer, até que se ponha em ação. No momento em que atua, não é o passado que atua sobre o presente, porém, algo que se estende até ao presente (STEIN, 2012, p. 126), o que significa que o ato de vontade náo caiu no esquecimento: existe no modo de "atualidade" e no modo de "passividade". Enquanto tal, pertence à essência da consciência, porque o eu vive numa série de atos de "pano de fundo", de inatualidades que não são já, ou não são ainda cogito (conscientes) e, portanto, ainda não estão acessíveis à reflexão; para serem compreendidos, têm que passar pela forma do cogito (STEIN, 2012, p. 126). O mesmo se poderia dizer de certas vivências da infância, pois "[...] tudo o que penetra em estado vivo no presente pode ter um efeito, qualquer que seja a distância que separa do presente o ponto de partida do vivido eficiente." (STEIN, 2012, p. 126-127).

Neste ponto, acentua-se uma certa permanência dos atos vividos que fazem parte da consciência e que precisam do tempo para se tornarem ativos. O tempo apresenta assim o paradoxo do ser humano, porque se, por uma parte, é necessário para a realização do ser humano, é, por outra, também o que manifesta a sua finitude. 


\subsection{TEMPORALIDADE E FINITUDE}

O que tem necessidade do tempo, para se tornar o que é, é algo de limitado, colocado no ser como "algo" e náo como "um todo" - e nisto consiste o sentido da finitude. A noção de potencialidade assegura a permanência, mas, por outro lado, é índice da finitude, está ligada ao devir, ao tempo, à necessidade de passar. A sua dimensão não é senão a da progressão da atualidade. $\mathrm{O}$ seu ponto cardeal fixo é o presente que passa (STEIN, 1972, p. 46):

O que [...] é ao mesmo tempo atual e potencial tem necessidade do tempo para passar de um ao outro. O ser atual-e-potencial é o ser temporal. O ser temporal é do movimento existencial: é um ressurgimento perpétuo da atualidade. $\mathrm{O}$ ente que é temporal não possui o seu ser mas este é-lhe dado de novo em cada vez. De onde se apresenta a possibilidade de um início e de um fim do tempo. Deste modo uma das significaçóes da finitude encontra-se circunscrita: o que o ser não possui mas que tem necessidade do tempo para chegar ao ser, seria portanto o finito. (STEIN, 1972, p. 67).

O tempo revela, pois, a finitude do ser humano, uma vez que a corrente puntiforme encontra alguns momentos intermitentes, lapsos não abarcáveis pela memória. O "eu vivo", que em si dá a vida aos seus conteúdos de experiência, não pode, porém, emprestar-lhes a atualidade do "ser vivo pleno", porque lhe escapam temporalmente devendo reatualizá-los com novos atos vivificadores: "[...] a temporalidade fenomenológica passa agora a cifra da deficiência de quem há-de ser sustentado em cada momento no ser." (FERRER,1998, p . 848). De facto, a atualidade da consciência não é a de um ato puro que abarque o todo da consciência; a sua atualidade tem de se refluir continuamente, através dos movimentos de protensão e retensão. ${ }^{7}$ No entanto, o momento passado e o momento futuro não são simplesmente não-ser. "O ser momentâneo, atual, puramente ôntico, não é pensável como existente só por si [...]; fenomenologicamente dá-se algo como que, surgindo da obscuridade, atravessa um raio de luz para mergulhar de novo na obscuridade." (STEIN , 2003, p. 60). Surge um ponto culminante dentro de um fluxo. Podemos compreender que há um ser que dura, contudo, que na duração não é atual. No que sou agora, insinua-se algo que atualmente náo sou, mas que se tornará atual no futuro.

\footnotetext{
7 Há uma certa correspondência entre a noção husserliana de protensão e retensão e a noção steiniana de ato e potência (GERL-FALKOVITZ, 1998 p. 174. nota 45).
} 
A temporalidade bifurca-se assim em temporalidade da doação, para um eu que provê de vida as suas experiências, e em temporalidade própria da realização da essência, que é a que dota do seu quid idêntico o composto temporal. Ambas, temporalidade própria e temporalidade da doação, são condição necessária para a manifestação consciente do indivíduo e para a sua efetividade, e são, ao mesmo tempo, índice revelador de uma limitação ontológica (FERRER, 1998, p. 851; STEIN, 1972, p. 80).

Ato e potência manifestam-se, por conseguinte, como factos antropológicos fundamentais, os quais estão estritamente ligados com a temporalidade. Se Stein inicia o tema da sua obra Ser finito e ser eterno pela concepção tomista da doutrina do ato e da potência, entretanto, essa visão será completada pela concepção agostiniana do ser e também do tempo (STEIN, 1972 , p. 4-5). A autora compreende que o enigma da existência e a questão do tempo entram em jogo, ao mesmo tempo. De maneira análoga a Heidegger, Stein percebe que somente dando uma resposta ao tempo se dá uma resposta à existência (GERL-FALKOVITZ, 1998a, p. 167). Na verdade, o tempo é criado pelo movimento existencial, que luta contra o nada e se volta para o ser:

É o movimento primitivo existencial que cria - como seu "espaço"- para si o tempo. "No ponto de contacto existencial, existe o tempo. E este precisamente produz-se enquanto presente". "O tempo é o presente passando pelo ponto de contacto existencial". O passado e o futuro não são pressupostos pelo presente, mas existem "com o presente e em relação a ele", pois que saem do nada e mergulham no nada; fazem parte do movimento primordial enquanto dimensōes formais vazias. (STEIN, 1972, p. 46).

Stein realça que o ser do eu é, por isso, um ser continuamente mutável, mas, precisamente por isso, algo de recebido. O ser humano é posto na existência e é conservado nela, de um momento ao outro. As unidades de experiência, das quais o ser é um devir e uma passagem, têm necessidade do eu para chegar à existência, mas o ser que elas recebem do eu não é eterno e imutável, é devir e passagem, com um certo nível de ser. O ser humano recua com horror diante do nada e exige não apenas uma continuação do seu ser, mas também uma posse plena do ser (STEIN, 1972, p. 61). Neste ponto, situa-se a crítica que Edith Stein tece a Heidegger, para quem a finitude temporal coloca o homem "diante do ser". Segundo Stein, a finitude faz o homem procurar o que é infinito ou intemporal para receber dele o ser. 


\section{Crítica a Heidegger}

Como é noto, Edith Stein tinha colocado o seu ensaio A fllosofia existencial de Martin Heidegger (SECRETAN, 1987, p. 62; GERL-FALKOVITZ, 1998, p. 143$)^{8}$ como apêndice à sua obra Ser finito e ser eterno. Tal apêndice indicaria que a autora admira as análises de Heidegger sobre o ser humano e que a obra Sein und Zeit teve influência sobre o seu pensamento. ${ }^{9}$ Por outro lado, significaria também a sua distanciação em relação às posições heideggerianas, principalmente a concepção do ser humano como um ser apenas circunscrito à dimensão temporal e à finitude do Dasein (CABALLERO BONO, 2012). Sein und Zeit, que a autora leu já no verão de 1927, parecia-lhe uma obra importante, como ela própria escreve ao seu amigo Roman Ingarden, nesse mesmo ano:

Que Heidegger seja algo de grande e que pode meter-nos a todos no bolso, acredito-o também por causa do seu livro. Antes não o sabia, ou mais precisamente via somente os efeitos; a sua grande influência sobre a geração mais jovem. Li o livro na sua maior parte nas férias, porém não o terminei por completo; comparando com as coisas que nessa altura me pressionavam, terminá-lo perdeu importância para mim. (STEIN, 2001, p. 792).

\subsection{AdMiraÇáo E DistanCiaÇáo}

$\mathrm{O}$ interesse antropológico era certamente um ponto comum a ambos os autores, bem como a pergunta pelo sentido do ser. No entanto, Edith Stein refere, em 1931: "[...] é uma obra grandiosa mas a mim estranha." (CABALLERO BONO, 2012, p. 101). Estranha, pois circunscrevia o ser humano a uma "teleologia imanente", a uma hermenêutica da "temporalidade

\footnotetext{
8 Philibert Secretan escreve, em nota: “Primitivement publiées en annexe à Endliches und ewiges Sein, les études sur la Philosophie de l'existence de Heidegger ont, par suite, été intégrées au volume VI des Werke. Ces études constituent le chapitre VI du présent ouvrage." (STEIN, 1987, p. 62, nota 5); Gerl-Falkovitz, por sua vez, destaca: "Con il titolo Martin Heideggers Existentialphilosophie, [...] questa critica aprofondita è statta publicata per la prima volta nel 1962, separatamente da Essere finito e essere e eterno." (GERL-FALKOVITZ, 1998, p. 143).

9 Gerl-Falkovitz enfatiza: "Allorchè Edith Stein nel 1936 rielaborerà nel Carmelo il suo abozzo incompiuto nella grande opera Endliches und ewiges Sein [...], le diede un sottotitolo quase provocatorio: Saggio (tentativo) di una ascesa al senso dell'essere. In questo modo vienne ripresa la questione fondamentale di Sein und Zeit [...] del 1927 da lei letto 'subito dopo la publicazione e da cui ricevette una forte impressione, senza pero giungere ad afrontare in modo oggetivo il dibatito sull'argomento." (GERL-FALKOVITZ, 1998, p. 143). "La Stein fu molto impressionata da Sein und Zeit di Heidegger; tanto fortemente ella sentì la necessità di definire la sua posizione nei confronti di quella di Heidegger." (Hans Rainer SEPP: “Introduzione”, in: STEIN, 2003, p. 20, nota 30).
} 
quotidiana"; e, na expressão de Stein, marcada pela "má consciência”. Má consciência, enquanto acentua a consciência da culpa e da negatividade. E, além disso, caracterizada por uma ambiguidade, visto que pretende tratar do ponto de vista ontológico o ser do Dasein, mas, por vezes, permanece no plano ôntico (CABALLERO BONO, 2012, p. 105). Por outro lado, a autora aprecia que Heidegger tenha colocado a relação ser-tempo como tema central da sua obra; era, de facto, um tema importante na filosofia da época. O tempo era um tema caro ao seu mestre, e precisamente o tema do ser tinha sido colocado também por Husserl, porém, não tinha sido desenvolvido.

De onde lhe vem então essa sensação de estranheza que lhe causou a leitura de Sein und Zeit? Em parte, esta pode explicar-se pelo facto de, nessa altura, Stein estar a traduzir a obra de S. Tomás de Aquino, Quaestiones disputatae de veritate (CABALLERO BONO, 2012, p. 108). Para Stein, se o tempo revela ao ser humano a sua finitude, revela também que este é um ser criado, que necessita de ser sustentado em cada momento pelo ser; o seu ser é um ser recebido. Como assinala Caballero Bono, a Erschlossenheit (abertura ou “estado de aberto") deve ter provocado em Stein admiração; ela própria utiliza esse conceito no sentido do espírito como abertura da pessoa (CABALLERO BONO, 2012, p. 102; STEIN, 2003, p. 384). O ponto em que Edith Stein se póe diretamente em contraste com Heidegger é que o ser se resolve apenas na "hermenêutica da temporalidade"; como se, desde o princípio da obra, quisesse demonstrar a temporalidade do ser, aprisionando toda a possibilidade de abertura à eternidade, considerando o Dasein apenas como um ser finito. No devir temporal, manifesta-se a finitude do ser humano. A vida do eu, por um lado, vem do passado e está projetada no futuro, está como em Heidegger "lançada" na existência. Todavia, por isso mesmo, a existência exige compreender como foi lançada na existência e de reconhecer de onde recebe a vida e o ser (STEIN, 1972). ${ }^{10}$

Se, de uma parte, a concepção de Stein a propósito do ser e do tempo se revela próxima da concepção heideggeriana, enquanto ela reconhece que o ser humano está "lançado na existência" e está em devir, de outra parte, a finitude é para Stein o que leva a fazer um salto e a mostrar a necessidade ontológica de que o ser temporal, finito, se ligue ao ser transcendente para receber dele o ser.

\footnotetext{
${ }^{10}$ A autora comenta, em nota, referindo-se a Sein und Zeit de Heidegger: "[L'existence humaine] exige quelqu’un qui jette le 'jetté. Ainsi se dévoile l”être jeté’, comme être créé.” (STEIN, 1972, p. 59).
} 


\subsection{TEMPORALIDADE E SENTIDO DO SER}

No ensaio A filosofia existencial de Martin Heidegger, depois de expor de maneira clara e sintética os elementos essenciais da obra Ser e Tempo, Stein passa a uma tomada de posição, respondendo a três questôes: $\mathrm{O}$ que é o Dasein? A análise do Dasein é consistente? Oferece um fundamento suficiente ao sentido do ser? Retomando o tema da "abertura" como "poder-ser" e o "ser para-a-morte" como o "ser-para-o-fim", Stein questiona a experiência própria da morte e a questão do destino da alma: esta exige, de certa maneira, o repensamento da questáo da temporalidade:

A consideração da morte deveria ajudar-nos a compreender o ser autêntico ao qual está chamado o homem do Dasein quotidiano: um ser no qual o homem se dispóe ele mesmo a uma outra maneira de ser, e se desliga da vida quotidiana na qual está empenhado. (STEIN, 1987, p. 102).

Segundo a autora, a questão da morte pensada como uma possibilidade exige a verdadeira compreensão das "possibilidades próprias" e a correspondência às exigências do instante. Tais exigências necessitam da compreensão da essência do homem ou da sua especificidade, a qual é dada ao homem e na qual, precisamente, este é "lançado na existência"; mas, para que se desenvolva, tem necessidade da sua livre participação. Para compreender o instante, na opiniấo de Stein, é necessária a compreensão de uma ordem e de um plano que o homem não concebeu, no qual está implicado e deve assumir aí o seu papel (STEIN, 1987, p. 102-103). A passagem do plano ôntico ao plano ontológico implica uma fenda da temporalidade, dado que, na azáfama do dia a dia dos afazeres quotidianos, não se acorda nunca ao instante.

Por instante deve entender-se aqui não um simples facto pontual, ou uma cesura entre dois segmentos, entre passado e futuro; mas "[...] instante significa ponto de contacto de algo que não é temporal, mas que penetra na esfera do tempo." (STEIN, 1987, p. 103). Esse "ponto de contacto" exige uma erradicação da duração, pois não se trata de um instante fugitivo: algo nos surpreende no instante e é necessário tomar tempo para aí permanecer. É necessário esgotar o que o instante tem para oferecer. Isso implica que nós nos abramos a ele e aí nos ofereçamos; pois, sendo o nosso ser temporal, podemos integrar nele o intemporal, podemos conservar algo do que já foi e, desse modo, compreender que o nosso ser náo se esgota no temporal (STEIN, 1987): 
A incapacidade do nosso ser temporal de desdobrar a nossa natureza e de esgotar o que se oferece ao nosso poder de acolher, e a nossa impotência em reuni-lo em nosso possesso, mostram que o ser autêntico do qual somos capazes na temporalidade [...] náo é o nosso ser em última verdade. (STEIN, 1987, p. 104).

Conforme Stein, não é a corrida de nada em nada, como em Heidegger, que permite compreender o nosso ser, mas somente a plenitude permite compreender por quê, para o homem, "está em jogo o seu ser". Este não é somente uma extensão no tempo nem antecipação de si mesmo. $\mathrm{O}$ homem requer poder receber sempre de novo o ser, a fim de poder esgotar o que o instante lhe dá e ao mesmo tempo lhe tira (STEIN, 1987, p. 105).

Ora, nessa questão, pode observar-se uma diferença fundamental entre Stein e Heidegger; para este último, é o poder de antecipar o futuro, de se projetar, que marca e reúne as três ex-ktases temporais; enquanto, para Stein, é o presente, e nomeadamente o instante, que tem um privilégio, na esteira de Santo Agostinho e Husserl. Como a própria autora enfatiza, de maneira quase poética:

Este ser não é somente extensão no tempo e deste modo sempre diante de si; o homem aspira continuamente a receber o ser para poder esgotar o que o instante lhe dá e lhe tira. O que lhe dá plenitude não o quer deixar; e queria ser sem fim nem limites para o poder possuir totalmente e eternamente. Alegria sem fim, felicidade sem sombra, amor sem limites, vida potenciada ao máximo, ato o mais pleno possível de energia que seja ao mesmo tempo paz profunda e perfeito relaxamento - tal é a bem-aventurança eterna. Eis o ser que no Dasein está em jogo. (STEIN, 1987, p. 105).

Como se pode depreender do que foi referido acima, “[...] é a segurança que protege o homem do contínuo perigo que o ameaça e o 'coloca diante do ser'.” (GERL-FALKOVITZ, 1998, p. 171); mesmo se, em proa à fugacidade, faço a experiência que "[...] no meu ser finito englobo um ser durável" (STEIN, 1972, p. 64).

O presente é central para Stein, nomeadamente a noção de instante na qual "o ser se dá", ou melhor, no qual o eu "recebe o ser". Mas, de onde vem esse ser recebido? Em Ser finito e Ser Eterno, Stein refere que duas respostas são possíveis filosoficamente: ou o eu recebe a vida dos mundos do além, pelas 
experiências provocadas no eu pelo mundo exterior ou interior ou pelos dois ao mesmo tempo. Ou, entáo, o ser humano deve o seu ser imediatamente ao ser puro que, eternamente imutável, é de si mesmo e por si mesmo, mestre e inteligível (STEIN, 1972, p. 60; GERL-FALKOVITZ, 1998, p. 171).

As duas respostas não se excluem, em todo caso, o receber pressupóe um dar e só o ser puro seria capaz do dom da vida, mesmo se a comunica através destes mundos. A ideia do ser supremo constitui, pois, para cada eu, a medida do próprio ser: "A ideia do ato puro ou do Ser eterno uma vez apreendida pelo eu, torna-se a medida do seu próprio ser." (STEIN, 1972, p. 62). Essa ideia é fundamental para a elaboração da sua ontologia, mas é também nela que o ser humano, sendo finito e temporal, assenta para encontrar a segurança que a temporalidade em si mesma não pode dar. No entanto, faz pensar a análise de Stein, ao mostrar que o eu esteja, pela sua natureza e no seu papel de unificação das vivências, para além do tempo - embora este para-além se reduza a um momento apenas.

\section{CONSIDERAÇÓES FINAIS}

Stein é influenciada por Heidegger, como também já por Husserl, na compreensão da "constituição temporal do ser humano". Contudo, considera que, no presente, o ser humano, mais do que encontrar-se com a "angústia do nada", encontra-se com a necessidade e com o desejo de receber em si a plenitude do ser; esta se mostra "mais originária" do que a angústia, pois todo o ser humano anseia pela plenitude. Como sublinha Bénédicte Bouillot, "[...] a análise fenomenológica vem revelar a ideia dum ser que é ato puro, e ao mesmo tempo, o desejo do ser finito por uma tal plenitude de ser." (BOUILLOT, 2015, p. 240). Pelas noçôes aristotélico-tomistas de ato e potência, Stein explicou um ser que está em devir, que é ser e não-ser. Não obstante as limitaçôes ontológicas da existência e as intermitências entre uma vivência e outra, é possível uma continuidade existencial. Por outro lado, evidencia que é no presente, precisamente onde sente a sua finitude, que o ser humano se abre à plenitude do ser. Por tal motivo, o tempo para Stein não pode ser pensado sem a relação ou "abertura" à eternidade.

De acordo com Stein, não basta ao ser finito compreender o ser como "algo". Dizer que o eu (Dasein) é lançado na existência leva-nos a levar em conta que, se este é "um ser lançado", é necessário "alguém que lance o lançado". Desse modo, desvela-se o "ser lançado" como "ser criado" (STEIN, 1972, p 
. 59). ${ }^{11}$ Para Edith Stein, admitir que o homem é criado por Deus é admitir que o ser finito "[...] lhe assemelha mais do que todas as outras coisas que fazem parte da nossa experiência: precisamente porque é um eu, uma pessoa." (STEIN, 1972, p. 345; DE RUS, 2006, p. 50-51).

Heidegger dá o privilégio ao futuro que coloca o homem "diante do ser”. Sem negar a importância dada ao futuro, Stein mantém sempre, pelo contrário, o privilégio do presente e critica a "[...] supervalorização geral do futuro" (STEIN, 1987, p. 106). Bénédicte Bouillot, com razão, comenta que, na opiniâa de Stein, na análise de Sein und Zeit, tudo parece pensado para justificar um homem sem Deus, ou reservando para o homem o estatuto de um pequeno deus (BOUILLOT, 2015, p. 240). ${ }^{12}$

Em conformidade com a sua formação inicial, mas com um cunho que lhe é próprio, de abertura aos valores, à pessoa e ao ser, Stein segue a linha fenomenológica em diálogo com a ontologia. Heidegger, por sua vez, segue a via da hermenêutica, procurando um novo questionamento sobre o "sentido do ser", mas permanecendo no horizonte da transcendentalidade imanente, da finitude, excluindo da temporalidade a noção de eternidade (DASTUR, 2011, p. 566). ${ }^{13}$ Busca na própria finitude a autenticidade do Dasein, no cuidado e na abertura ekstatica, pela qual distingue a temporalidade originária da concepção vulgar do tempo. Entretanto, podemos questionar-nos se, na abertura ao passado e no cuidado de si, compreendendo o seu destino na historicidade, o homem pode encontrar a segurança e o sentido do seu próprio ser.

Heidegger teve o mérito de pensar o ser humano como um poder-ser, como abertura a si próprio e à própria finitude. Stein, por sua vez, demostra que a finitude exige a plenitude, exige a segurança que não pode vir da própria finitude. O tempo, em si mesmo, não pode explicar-se, se não como revelador da própria finitude; mas como sublinha também P. Ricoeur, a finitude,

\footnotetext{
${ }^{11}$ Veja-se nota 40.

${ }^{12} \mathrm{Na}$ página acima citada, a autora sublinha, a propósito do conceito de essência e existência, que Heidegger pretendia que, para o Dasein, esses dois conceitos coincidissem, enquanto na filosofia tomista e na tradiçáo cristá só em Deus, ato puro, essência e existência coincidem; a autora sublinha que Heidegger parece atribuir assim ao homem o estatuto de um pequeno deus.

13 “[...] penser l'éternité et la mort, c'est précisément ce que conteste radicalement d'entrée de jeu Heidegger dans la conférence intitulée 'Le concept de temps', qu'il prononce en juillet 1924 devant la société de théologie protestante de Marburg. Il ne s'agit plus, explique-t-il, de considérer que 'le temps trouve sons sens dans l'éternité', mais au contraire de comprendre le temps à partir du temps." (DASTUR, 2011, p. 566).
} 
entendida como ser para-a-morte, ou melhor, como sublinha Dastur ${ }^{14}$, em direção à morte, não pode mostrar o caminho da vida sem fim (RICOEUR, 2007).

No entanto, na nossa época, há uma concepção do "presente adiado", sem horizonte de futuro, como assevera o psiquiatra italiano Vittorino Andreoli (2010), e sem uma verdadeira abertura à subjetividade própria; perguntamo-nos se não seria necessário um diálogo entre a "hermenêutica da temporalidade", ao jeito de Heidegger, fazendo uma releitura do passado, e a análise de Stein, a qual leva até às últimas consequências a noção de "abertura", considerando-a como abertura à dimensão intemporal, eterna.

Em nosso entender, a noção heideggeriana de reencontro com o passado pode ter uma certa atualidade, enquanto "análise preparatória" para passar de um nível ôntico a um nível ontológico da temporalidade, já que somente a reconsideração do passado pode levar a uma maior verdade do presente, como ressalta Heidegger. De alguma maneira, a via hermenêutica da temporalidade intramundana poderia servir de análise preparatória para a compreensão da linha fenomenológico-ontológica de Stein. Seguindo o pensamento de Stein, o "[...] presente deve ser reconhecido como o modo de ser da realização, que nos abre - numa brecha fulgurante de luz eterna - a compreensão e a realização do ser; e o passado como o modo de ser que, no meio da fugacidade do nosso ser, comunica a impressão da constância.” (STEIN, 1987, p. 106).

NUNES, E. P. L. Consciousness and temporality in Edith Stein: dialogue with M. Heidegger.Trans/form/ação, Marília, v. 44, n. 1, p. 95-116, Jan./Mar., 2021.

\footnotetext{
ABSTRACT: The theme of consciousness and temporality is common to phenomenological and hermeneutic philosophy. In this article we intend to present Edith Stein's theory of time, based on her fundamental work: Finite and Eternal Being. It's built in the wake of Husserl's phenomenology, and as a reaction to Heidegger's Sein und Zeit, and also relies on the theory of the act and potency of Thomas Aquinas. Stein constructs a theory of time centered on the present. Applying phenomenology to 'units of experience', and the concepts of 'act' and 'potency' of Thomist origin, the concept of 'actuality' is

14 "Heidegger lui-même, dans une lettre adressée à Hannah Arendt et daté du 21 avril 1954, a attiré l'attention sur la 'grave erreur' qui “ s'est répandue du fait des premières traductions françaises - et qu'il n'est presque plus possible d'éradiquer à présent - à savoir la traduction de Sein-zum Tode par être pour la mort, au lieu de vers la mort." (DASTUR, 2011, p. 572).
} 
created, which comprises the three temporal dimensions. Criticizing Heidegger, the author emphasizes that the 'being of the finite being' is 'a being received', which constitutes the relationship of 'openness' to 'eternal being'. In conclusion we propose the possibility of reencounter with the past (Heidegger) as a preparatory analysis for the 'opening' to the eternal being.

KeYwords: Temporality. Finiteness. Actuality. Present. 'To be received'.

\section{REFERÊNCIAS}

ACQUAVIVA, Marcelo. Edith Stein - Dal senso dell'essere al fondamento eterno dell'essere finito. Roma: Armando, 2002.

AGOSTINHO, Santo. Confessiones. Tradução de J. Oliveira Santos e Ambrósio de Pina. Confissóes, Braga: Livraria do Apostolado da Imprensa, 1990.

ALES BELLO, Angela. Fenomenologia dell'essere umano. Lineamenti di una filosofia al feminile. Roma: Città Nuova,1992.

ALES BELLO, A. Il problema dell'essere in Edith Stein e Hedwig Conrad-Martius. Aquinas, v. 45, n. 3, p. 17-28, 2002.

ANDREOLI, Vittorino. Giovani e futuro. Discorsivo Magazin. Disponível em: http:// www.discorsivo.it/magazine/2010/12/20/vittorino-andreoli-giovani-e-futuro/. Acesso em: 30 jun. 2017.

AQUINO, Tomás de. De ente et essentia. Trad. Catherine Capelle. L'être et l'essence. Paris: Vrin, 1971.

AQUINO, Tomás de. Questionis disputatae, de potentia. Trad. italiana di A. Campodonico. La potenza di Dio. Firenza: Nardini, 1991.

BERGSON, Henry. Essai sur les données immédiates de la conscience. Paris: Alcan, 1921.

BOUILLOT, Bénédicte. Le noyau de l'âme selon Edith Stein: De l'épochè phénoménologique à la nuit obscure. Paris: Hermon, 2015.

CABALLERO BONO, José Luis. Sentido y alcance de la empatía en Edith Stein. Burgense, v. 43, p. 395-419, 2002.

CABALLERO BONO, José Luis. En torno a la hermenéutica blanca de Ser Tiempo en Edith Stein. Veritas, v. 27, p. 97-112, 2012.

DASTUR, Françoise. Heidegger et la question du temps. Paris: PUF, 1990.

DASTUR, Françoise. La critique ricœurienne de la conception de la temporalité dans l'Être et le temps de Heidegger. Archives de Philosophie, v. 74, p. 565-580, 2011.

FERRER, Urbano. Temporalidad y historia en Edith Stein. Anuário Filosofico, v. 31, p. 843-869, 1998. 
GERL-FALKOVITZ, Hanna-Barbara. Philosophie, Mystik, Leben, Mathias: Grüewald, 1991, Traduzione di Giuliano Sansonetti. Edit Stein, Vita-Filosofia-Mistica. Brescia: Morcelliana, 1998a.

GERL-FALKOVITZ, Hanna-Barbara. Essere finito ed eterno: L'uomo come immagine della trinità. Edith Stein, Simposio internazionale, testimoni per oggi, profeti di domani, Roma: Teresianum, 1998b. Disponível em: http://www.ocd.pcn.net/edsi_han.htm. Acesso em: 22 set. 2017.

HEIDEGGER, Martin. Sein und Zeit. Frankfurt am Main: Vittorio Kosterman, 1977.

LOTZ, Johannes B. Martin Heidegger et Thomas d'Aquin. Traduction de Philibert Secrétan. Paris: PUF, 1988.

PRZYWARA ,Erich. Analogia entis. Einsiedeln: Johannes, 1962. Traduction française de Philibert Secrétan. Paris: PUF, 1990.

RICOEUR, Paul. Vivant jusqu’à la mort. Paris: Seuil, 2007.

RUS, Éric De. Intériorité de la personne et éducation chez Edith Stein. Paris: CERF, 2006.

SCHULZ, Peter. Il concetto di coscienza nella fenomenologia de Husserl e di E. Stein. Aquinas, v. A. 39/2, p. 291-305, 1996.

SECRETAN, Philibert (Présenté et traduit par) STEIN, Edith. Phénoménologie et philosophie chrétienne. Paris: CERF, 1987a.

SECRETAN, Philibert. De Husserl a Thérèse d'Avila, la question de la personne. In: STEIN, Edith. Phénoménologie et philosophie chrétienne. Présenté et traduit par Philibert Secrétan. Paris: CERF, 1987b. p. 161-164.

SEPP, Hans Rainer. Introduzione a Edith STEIN. In: STEIN, E. Potenz und Akt. Studien zu einer Philosophie des Seins. Werke, Band XVIII, Herder, Freiburg-Basel-Wien 1998; tr. it. Potenza e atto: studi per una filosofia dell'essere, Roma, Città Nuova, 2003, p. $13-47$.

STEIN, Edith. Endliches und edwiges Sein. Versuch einesaufstiegs Zum sinn des Sein. In: Edith Stein Werke. Band II, Herder KG, Freiburg i.: Br. 1950; L'Être fini et l'être Eternel, Essai d'une atteinte du sens de l'être, traduit de l'allemand par G. Casella et F. A. Viallet. Paris: Nauwelaerts/Louvain: Beatrice-Nauwelaerts, 1972.

STEIN, Edith. La Philosophie de l'existence de Martin Heidegger. In: STEIN, Edith. Phénoménologie et philosophie chrétienne. Présenté et traduit par Philibert. Secrétan, Paris: CERF, 1987. p. 63-130.

STEIN, Edith. Der Aufbauder menschichen Person. In: Edith Steins Werke, Band XVI, Herder, Friburg i. Br.- Basel-Wien (1994); La estructura de la persona humana, traduzido por José Mardomingo, Madrid: Biblioteca de Autores Cristianos, 1998. 
STEIN, Edith. Obras completas I. Escritos autobiográficos y cartas. Vitoria/Madrid/ Burgos: El Carmen/Espiritualidade/Monte Carmelo, 2001.

STEIN, Edith. Potenz und Akt. Studien zu einer Philosophie des Seins. In: STEIN, Edith. Werke, Band XVIII, Herder, Freiburg-Basel-Wien (1998); tr. it. Potenza e atto: studi per una filosofia dell'essere, a cura di A. Ales Bello, Roma, Città Nuova, 2003.

STEIN, Edith. Zum Problem der Einfünhlung. ESGA5, Herder (1917), 2008, Le problème de l'empathie. tradduction de Michel Dupuis, Revue par Jean-François Lavigne. Toulouse: Carmel/Paris: CERF, 2012. 